\title{
A DIGNIDADE DO TRONO E A REGENERAÇÃO DO PACTO SOCIAL: A MEMÓRIA DO VISCONDE DE GOIANA A DOM PEDRO I
}

\section{Guilherme Del Negro ${ }^{1}$}

\section{Resumo}

O artigo analisa a Memoria sobre as principaes cauzas, por que deve o Brasil reassumir os seus direitos, e reunir as suas províncias, do Visconde de Goiana, de modo a exemplificar como a convocação da Assembleia Nacional Constituinte e Legislativa de 1823 se compatibilizava com uma interpretação conservadora do regime monárquico-constitucional.

Palavras-chave: Assembleia Nacional Constituinte e Legislativa de 1823, Visconde de Goiana, restauração conservadora, regime monárquico-constitucional

Os anos que antecedem a convocação da Assembleia Nacional Constituinte e Legislativa de 1823 e sucedem a instalação das Cortes Portuguesas são um período de grande interesse para a discussão sobre os fundamentos do regime político brasileiro de então. Se, uma década antes, a ideia de instalação de uma Assembleia Nacional Constituinte parecia uma noção restrita aos grupos mais radicais do Reino, especialmente àqueles de tendência republicana, em meados de 1822 ela já se tornara "uma aspiração geralmente aceita no Brasil" (RODRIGUES, 1974, p.22). Até mesmo integrantes dos grupos moderados e conservadores, como no caso do jornalista Luís Augusto May, que ainda defendiam a manutenção da união entre Brasil e Portugal, apoiavam a convocação de uma assembleia constituinte estritamente brasileira.

Como mostra Lúcia Maria das Neves, em Corcundas e Constitucionais, a instalação das Cortes Portuguesas fomentou debates no país sobre a configuração do regime monárquico-constitucional, opondo, de um lado, os Corcundas, que compactuavam com as determinações das Cortes Portuguesas, a, de outro lado, os Constitucionais, que afirmavam serem despóticas as Cortes Portuguesas, por imporem ao Brasil obrigações de modo unilateral (NEVES, 2003).

Os próprios constitucionais, por sua vez, não formavam um grupo coeso: muitos dos que rejeitavam as Cortes Portuguesas temiam que a ruptura pudesse levar a uma "anarquização do país". Essas divergências acabaram se acirrando na Assembleia Constituinte e Legislativa do Brasil, culminando com a sua dissolução, após a multiplicação de expressões de matriz republicana, que, segundo o Imperador, produziriam partidos

\footnotetext{
${ }^{1}$ Doutorando em Direito - Universidade de Brasília (UnB). Professor Assistente - Instituto Rio Branco (IRBr). E-mail: guilhermedelnegro@gmail.com
} 
incendiários (RODRIGUES, 1974, p. 214). Se no fim prevaleceu a ruptura como solução de força, sendo a ameaça de anarquia invocada como pretexto para autorizar a ação da tropa - a qual já se encontrava previamente mobilizada e preparada, especialmente por seus contingentes portugueses -, a convocação da Assembleia pelo Príncipe Regente se baseou em um conjunto de doutrinas conservadoras referentes à monarquia constitucional. Ademais, para boa parte dos políticos e escritores da época, a ideia da convocação era associada a um pensamento da restauração.

$\mathrm{Na}$ Assembleia, as primeiras rusgas entre as diferentes concepções foram sentidas rapidamente, antes mesmo de começarem as deliberações de fato sobre o projeto constituinte, quando José Custódio Dias, na terceira sessão plenária preparatória, insistiu em que o Imperador não deveria ocupar lugar mais alto do que o do Presidente da Assembleia nas sessões a que comparecesse (RODRIGUES, 1974, pp. 42-43). Uma grande parcela de deputados moderados, que evitava qualquer confrontamento direto com o Imperador, tentou dissuadir o padre mineiro de "radicalizar" a sessão, começando por seu próprio presidente, o senador Vergueiro.

As noções de um pacto social e de uma constituição, associadas às revoluções liberais, puderam ser invocadas inclusive por monarquistas convictos e por partidários da manutenção dos vínculos luso-brasileiros. De modo a explorar essa suposta incongruência, volto a um momento anterior à convocação da assembleia braślica e apresento o escrito político de um personagem muito interessante, Bernardo José da Gama, o Visconde de Goiana, o qual sintetiza uma visão sobre a monarquia constitucional que se compactua com o projeto da Coroa. Trata-se do opúsculo Memoria sobre as principaes cauzas, por que deve o Brasil reassumir os seus direitos, e reunir as suas províncias (GAMA, 1822a), dedicado ao Príncipe-Regente em 10 de janeiro de 1822, no dia seguinte ao Ato de Vereação do Fico.

Nesse escrito, o autor apresenta os fundamentos para que se consolide a ruptura com as Cortes Portuguesas e propõe medidas para que o Brasil recupere sua parcela de soberania que the fora retirada, sem, contudo, sugerir uma desvinculação de Portugal. Trata-se de um escrito político associado a um pensamento da restauração, que admite a tomada de medidas excepcionais para o resgate da normalidade institucional, mas que já invoca categorias de cariz liberal, contudo com um sentido mais próximo daquele do Antigo Regime. Segundo Augusto Sacramento Blake, autor do principal catálogo bibliográfico do período, a obra do Visconde de Goiana foi do agrado de Dom Pedro, que teria mandado imprimir e distribuir no Reino novas cópias do escrito (BLAKE, 1883, p. 412).

De início, apresentarei uma curta biografia do personagem, que permite situar de forma mais adequada sua obra, seu interesse em redigi-la, suas convicções políticas e seus correligionários. Em seguida, analisarei a obra em questão, de modo a apontar como o autor mobiliza o discurso da representação nacional própria como uma defesa da dignidade da Coroa e como ele constrói as ideias de uma constituição com alcance limitado e de um 
pacto social monárquico. Os argumentos políticos de Bernardo José da Gama, personagem que oscilava entre o oportunismo e a lealdade, sempre do lado da Coroa, são especialmente úteis para ilustrar os usos do discurso em favor de uma concepção específica da monarquia constitucional que era compatível com os projetos da Família Real, mantendo em aberto uma ideia de reconciliação com Portugal e dando papel preeminente ao Imperador.

\section{BERNARDO JOSÉ DA GAMA, O VISCONDE DE GOIANA}

Bernardo José da Gama, o Visconde de Goiana, é uma das figuras públicas do Império cuja vida é mais permeada por episódios coloridos e anedóticos. Com isso em vista, causa estranheza a inexistência, até hoje, de obras de maior porte dedicadas à biografia desse personagem. Contudo, de modo a compor meu curto relato neste artigo, parto de duas coletâneas que possuem relatos sistemáticos sobre sua vida: Diccionario biographico de pernambucanos celebres, de Francisco Augusto Pereira da Costa (1882, pp. 212-222), e Vultos do Império, de Hélio Vianna (1968, pp. 31-73).2

Nascido em Recife, em 20 de agosto de 1782, Bernardo José da Gama, como vários jovens de famílias tradicionais de sua geração, fez seus estudos jurídicos em Coimbra, bacharelando-se aos 25 anos. Coincidentemente, finalizou seus estudos dois meses antes da transmigração da Corte ao Brasil, no que retornou ao país, em novembro de 1807, em um dos navios da esquadra que trazia a família real.

No país, viria a ocupar vários cargos públicos de grande relevo no Reino e no Império. Dotado de grande ambição e de uma singular capacidade de pleitear cargos e promoções, bombardeava seus superiores com requerimentos e ofícios, o que the rendeu a alcunha de "Pedinchão-Mor do Reino e do Império" (VIANNA, 1968, pp. 31-34). Ao que mostram os registros, não se esquivava de manifestar sua opinião e de criticar outros funcionários, no que angariou desafetos na maioria das posições que ocupou.

Poucos meses depois de retornar ao país, foi nomeado juiz de fora do Maranhão, função que exerceu até 1812. Foi demitido por influência do ex-governador José Tomás de Meneses, parente do antigo Vice-Rei do Brasil e Ministro do Reino Fernando José de Portugal e Castro. Meneses havia abandonado o governo da capitania após ter sido acusado por Bernardo José da Gama, então na condição de ouvidor interino, de ter interceptado e violado Cartas Régias.

Após pleitear nova posição e destinar acusações a várias figuras públicas no período de 1812 e 1814, foi finalmente designado para a ouvidoria de Sabará em 1815. Foi nessa posição que conquistou seu maior desafeto, José Teixeira da Fonseca Vasconcelos, o Visconde de Caeté, o qual acusou, juntamente a Antônio Gonçalves

\footnotetext{
${ }^{2}$ VIANNA, Hélio. Vultos do Império. Rio de Janeiro: Companhia Nacional, 1968, pp. 31-73. Essa obra é especialmente relevante por fornecer reparos à obra de Francisco Augusto Pereira da Costa, a qual claramente se baseia, em sua maior parte, nos próprios relatos, por vezes inexatos, do Visconde de Goiana.
} 
Gomide, dois futuros senadores do Império, de ter "rasgado os editais que proibiam a fabricação particular de pólvora e a proibição da leitura do periódico intitulado O Português" (VIANNA, 1968, p. 36).

Em 1822, Manoel de Freitas Pacheco, então juiz de fora de Sabará, aliado político do Visconde de Caeté, fez circular em apenso ao trigésimo-segundo número da Gazeta do Rio de Janeiro, de 14 de março de 1822, um impresso no qual acusava o "malvado" Bernardo de imputar ao Desembargador Teixeira "fatos mentirosos", e de ser "mentiroso, sem vergonha (...), armando testemunhos falsos, incriminando inocentes, arrancando folhas dos autos e metendo outras" (GAZETA DO RIO DE JANEIRO, 1822, p. 181). Foi seu tio, José Fernandes Gama, grande antagonista de Frei Caneca, quem saiu em sua defesa, publicando resposta em outro apenso, distribuído junto ao trigésimo-oitavo número da Gazeta do Rio de Janeiro, de 28 de março de 1822 (GAZETA DO RIO DE JANEIRO, 1822, p. 229). ${ }^{3}$ A troca de farpas foi satirizada pelo periódico A Malagueta, que qualificou a discussão como uma palhaçada entre libelistas famosos, no que Bernardo José da Gama mandou publicar um panfleto, em 16 de abril de 1822, a Resposta à Malagueta no. XII. ${ }^{4}$

Foi em Sabará que um dos episódios mais pitorescos da vida do ouvidor tomou lugar. Com a morte de D. Maria I em 20 de março de 1816, fixara-se o Ato de Aclamação solene de D. João VI para o ano de 1817. Contudo, em função da insurreição em curso em Pernambuco e da demora em obter o reconhecimento da sucessão pelas grandes nações europeias, a cerimônia foi adiada para o ano seguinte. Possivelmente para desaprovar seus conterrâneos e ignorando a suspensão das celebrações na Corte, o ouvidor mandou organizar na data originalmente marcada uma Aclamação em Sabará, com um grande cortejo (VIANNA, 1968, p. 36).

Em 1818, foi nomeado para servir em Lisboa, como corregedor do crime. Bernardo José da Gama atribui essa medida ao Visconde de Caeté que, aproveitando-se do fato de ele ser pernambucano e de ter parentes políticos na província rebelde, teria influenciado sua deportação a Portugal, embora ele nunca tivesse se envolvido com aqueles revolucionários que acusava abertamente de serem "partidários", integrando uma facção contrária ao bem geral. Em 1818, rumou à Corte, mas não seguiu viagem a Portugal.

Obstinado a ficar no Brasil, e a conseguir uma função na Corte, seguiu com sua campanha de requisições, que chegaram à atenção de D. João VI, que, segundo Hélio Vianna, teria registrado que "já lá tem mais requerimentos do suplicante" (VIANNA, 1968, p. 37). Em 1821, conseguiu ser nomeado para o Tribunal da

\footnotetext{
${ }^{3}$ Os dois apensos em questão não foram numerados ou paginados pelo jornal, e, por essa razão, não seguem a numeração de página da Gazeta do Rio de Janeiro. Os apensos não estão disponíveis nas digitalizações da Hemeroteca Digital da Biblioteca Nacional. Contudo, eles foram catalogados em coletânea física da Imprensa Régia em volume único, que já consta com versão digitalizada gratuita. Para facilitar a consulta dos leitores, os números de folha referidos neste artigo correspondem à sequência de encadernação adotada pela Imprensa Régia nesse documento, consolidada na paginação da versão digital. É à coletânea da Imprensa Régia que faço menção nas referências abaixo.

${ }^{4}$ GAMA, Bernardo José da. Resposta à Malagueta no. XII. Rio de Janeiro: Typographia Nacional, 1822b. Há breve resumo do episódio em: CAMARGO, Ana Maria de Almeida; MORAES, Rubens Borba de. Bibliografia da Impressão Régia do Rio de Janeiro. São Paulo: EDUSP/Kosmos, 1993, p. 413.
} 
Relação de Pernambuco, mas com isso não se satisfez - pela sua antiguidade e por julgar-se prestador de valiosos serviços à Coroa, queria uma função na Corte. Foi ainda nesse período, em que ambicionava conquistar o favor do Príncipe Regente, que escreveu o opúsculo Memoria sobre as principaes cauzas, por que deve o Brasil reassumir os seus direitos, e reunir as suas províncias.

No Rio de Janeiro, aliou-se ao grupo maçonico de Gonçalves Ledo (FELDMAN, 2014, p. 12), com quem continuou a trocar cartas por anos. Foi um dos redatores ${ }^{5}$ da famosa Representação do Povo do Rio de Janeiro ao Príncipe Regente em Prol da Convocação de uma Assembleia Geral, de 20 de maio de 1822 (BONAVIDES, 2002, pp. 571-579). Em 2 de julho, seguiu para Pernambuco, instruído a instalar o Tribunal da Relação e incumbido de uma missão sensível pela Coroa: tratar de convencer o governo pernambucano a apoiar a Assembleia Constituinte e Legislativa do Brasil, superando a "contumaz oposição da dita Junta de Governo", segundo o indica o Visconde de Cairu, que também elogia a indicação do governo para o tribunal. ${ }^{6}$

Eleito para a Assembleia Constituinte e Legislativa do Brasil, caiu enfermo menos de um mês depois de iniciados os trabalhos, ficando afastado por quarenta dias de suas funções, como atesta um Requerimento de 27 de maio de 1823 (BRASIL, 2003, p. 143). Mesmo nas sessões em que esteve presente, sua atuação como deputado constituinte foi pouco notável, à exceção das discussões sobre a liberdade de imprensa e sobre os crimes de calúnia e de difamação. Com a dissolução da Assembleia, rumou a Pernambuco para retornar a sua função de desembargador.

Quando desembarcou na província, em janeiro de 1824, já haviam começado os movimentos que desembocariam na formação da Confederação do Equador, os quais, ironicamente, haviam se iniciado justamente pela insubordinação da Câmara de Goiana. Sabedora das convicções políticas do desembargador, a Junta de Governo de Pais de Andrade mandou prendê-lo para que fosse então mandado de volta à Corte. Preso, negou-se a reconhecer Pais de Andrade como Presidente de Província e continuou a redigir ofícios, inclusive solicitando ajuda ao comandante John Taylor, enviado para depor Pais de Andrade e empossar Pais Barreto.

Saindo de Pernambuco, assentou-se na Bahia em junho de 1824, onde exerceu distintas funções judiciais. Em 1827, por fim, concretizou um de seus desejos de longa data, sendo nomeado para a Casa de Suplicação na Corte. No trajeto de Salvador ao Rio de Janeiro, o navio que o transportava foi capturado por corsários das beligerantes Províncias Unidas do Rio da Prata, no que perdeu algumas posses, que não viriam a ser indenizadas por tribunal de presas. $\mathrm{Na}$ Corte, chegou a ser Chanceler e Regedor das Justiças, quando redigiu um

\footnotetext{
${ }^{5} \mathrm{O}$ jornalista João Soares Lisboa revelou o nome dos seis autores do documento, de cuja produção participou como colaborador, em seu jornal: LISBOA, João Soares. Correio do Rio de Janeiro, Rio de Janeiro, no. 62, 27 de junho de 1822, p. 254.

${ }^{6}$ LISBOA, José da Silva. História dos principais sucessos políticos do Império do Brasil, dedicada ao senhor Dom Pedro I. Parte X, Seção III. Rio de Janeiro: Typographia Imperial e Nacional, 1830, pp. 26-29. No mesmo excerto, o Visconde de Cairu elogia a Memória apresentada por Bernardo José da Gama a Dom Pedro I nesse mesmo ano, pois "cheia de fiéis sentimentos e elevados princípios constitucionais" (pp. 26-27).
} 
projeto de Código de Processo Civil e Criminal em 1829, cujo trâmite não avançou e cujos artigos foram adotados em resoluções separadas.

No final de 1830, foi nomeado Presidente do Grão-Pará, mas não chegou a exercer essa função, por dificuldades em se chegar à província, então tomada por conflitos internos. A Noite das Garrafadas, em 13 de março, e a circulação da ríspida Representação ao Imperador, redigida por vinte e três deputados e um senador, no dia 17 do mesmo mês (BASILE, 2013, pp. 4-5), fizeram D. Pedro I destituir seu ministério português. O escolhido pelo Imperador para substituir o titular da principal pasta, o português José Antônio Silva Maia, foi Bernardo José da Gama, nomeado Ministro do Império no dia seguinte.

Com a nomeação do Ministério dos Marqueses, em 5 de abril de 1831, teve de abandonar seu cargo. Apesar de todas as controvérsias que cercam sua vida pública, sua lealdade para com a Coroa é atestada em ainda mais um episódio. Sendo reconduzido ao cargo junto a outros quatro ministros pela Regência Trina Provisória, demite-se em 26 de abril de 1831, alegando, com o típico exagero, que "se considerava coato e que protestava suportar o sacrifício só para socorrer à infância do Senhor D. Pedro II (...), mas que apenas as tropas depusessem as armas, no mesmo momento largaria o emprego" e que "os seus sentimentos eram verdadeiramente incombináveis com as excrescências de semelhante revolta" (GAMA apudVIANNA, 1968, p. 55).

Foi então nomeado novamente Presidente do Grão-Pará, mas somente ocupou o cargo por dezoito dias, sendo deposto pelo Comandante das Armas da província. Retornando à Corte, continuou a pleitear a responsabilização dos envolvidos, sem sucesso. O Ministro do Império, Lino Coutinho, com quem não mantinha boa relação, indicou-o para o Tribunal da Relação de Pernambuco, e, abolido o cargo de Chanceler nas Relações pela Disposição Provisória (FERREIRA, 1937, p. 44), foi indicado para ser subordinado de um Presidente da Relação com menor antiguidade do que a sua. Considerou essa medida um ataque direto a sua dignidade, retirando-se definitivamente da magistratura.

Interessantemente, foi então eleito deputado pela província do Grão-Pará para a legislatura de 1834/1837, servindo como tal em plenos anos de Cabanagem. Hélio Vianna destaca, de sua atuação na Câmara, a sua oposição à suspensão das garantias legais da província do Grão-Pará, em razão da revolta lá ocorrida; o reforço de sua postura antilusitana, opondo-se à assinatura de Tratado de Comércio e Navegação com Portugal e propondo a imposição de impostos sobre os comerciantes estrangeiros estabelecidos no Brasil; e sua condenação ao Ato Adicional de 1834, associado a Evaristo da Veiga, a quem deplorava abertamente (VIANNA, 1968, pp. 6467).

No fim da vida, apesar de reforçar sua campanha de requerimentos à Coroa, então representada por Dom Pedro II, alegando ter prestado valiosos serviços que deveriam ser recompensados com cargos públicos de importância e de boa remuneração, o Visconde de Goiana não exerceu muitas funções públicas. Foi suplente de 
deputado por Pernambuco e, por poucos anos, Inspetor da Caixa de Amortização. Sua última função, ocupada de 1850 até seu falecimento, foi a de ser o último Diretor do Curso Jurídico em Olinda (PINTO FERREIRA, 1977, p. 19), antes de a Escola de Direito de Pernambuco ser transferida para Recife.

\section{A MEMÓRIA DEDICADA A D. PEDRO I}

A Memória de Bernardo José da Gama, preparada no dia seguinte ao Ato de Vereação do Fico, é uma das primeiras obras dedicadas ao Príncipe Regente a apontar para a necessidade de se convocar uma representação própria brasileira distinta daquela convocada em Portugal, em resposta às medidas tomadas pelas Cortes Portuguesas no ano de 1821. Elogia a Representação do Governo, Senado e Clero de São Paulo (BRASIL, 1822), publicada uma semana antes, em 3 de janeiro de 1822, ao dizer que "sábios Paulistas, que fostes os primeiros a romper o véu do moderno despotismo" (GAMA, 1822a, p. 48). A proposta de Bernardo José da Gama de confederação das províncias antecede aquela que é considerada a primeira proposta oficial de se organizar uma assembleia brasílica (RODRIGUES, 1974, p. 21), qual seja, o discurso do Ministro José Bonifácio para a Convocação de um Conselho de Procuradores, de 26 de janeiro de 1822.

Muitos dos argumentos expostos nesse opúsculo são ecoados na famosa Representação do Povo do Rio de Janeiro ao Príncipe Regente em Prol da Convocação de uma Assembleia Geral, de maio de 1822, o que parece confirmar que o papel de Bernardo José da Gama na redação do documento não foi desprezível.

Na linha da Representação do Governo, Senado e Clero de São Paulo, na qual parece ter se inspirado em parte, Bernardo José da Gama critica a mudança de postura das Cortes Portuguesas, as quais teriam despojado o Brasil de sua unidade, ao determinar a administração provincial; de seu poder legislativo, ao determinar a criação das Juntas Provisórias de Governo; de seu poder executivo, ao determinar o retorno do Príncipe Regente a Portugal; de seu poder judicial, ao determinar a extinção dos tribunais superiores. Ao invocarem as Bases da Constituição, sem convocarem os representantes brasileiros como previsto no texto, as Cortes Portuguesas, conforme a constatação de Hipólito José da Costa, faziam com que o Brasil permanecesse um Reino somente em seu nome (BERNARDES, 2006, p. 503).

Diz então Bernardo José da Gama que caberia ao Brasil "tomar de reassumir os seus direitos” (GAMA, 1822a, p. 6). Seu opúsculo pretende explicitar as "ponderosas causas" que justificam a recuperação dos três poderes pelo Reino do Brasil e a ruptura com as Cortes Portuguesas. Tal ruptura não significa uma cisão de relações com Portugal, pois o autor, embora tenha se tornado crescentemente antilusitano ao longo da vida, ainda pretendia naquele momento "conservar a liberdade já adquirida e conservá-la ligada a Portugal" (GAMA, 1822a, p. 35), mostrando a "generosidade Brasílica" (GAMA, 1822a, p. 40) para uma reconciliação. A solução por ele desenhada passa por dar as rédeas da normalização dos Poderes Legislativo, Executivo e Judiciário ao Conselho 
de Estado, por convocar um Corpo Legislativo formado por Representantes das Províncias e por regenerar o pacto social (GAMA, 1822a, pp. 44-48).

\section{A dignidade do Trono e a sede natural do Império}

Ao iniciar a dissertação sobre as "ponderosas causas" para a ruptura com as Cortes Portuguesas, Bernardo José da Gama confirma a posição do antigo Ministro de Fazenda, Guerra e Negócios do Reino, Tomás Antônio de Vilanova Portugal ${ }^{7}$ de que, em caso de incompatibilidade, a prioridade da Coroa deveria ser a manutenção da ordem no Brasil, por se tratar da parte mais relevante do Reino Unido. Boa parte dos panfletos, discursos e documentos da época insistiam nesse ponto. Portugal, como um Império decadente, estaria tentando usar o peso do Brasil como âncora para sustentar suas pretensões de grandeza. ${ }^{8} \mathrm{O}$ Visconde de Goiana profere palavras ásperas, ao afirmar que os proponentes da nova organização política acreditavam "ser este o único modo de esconder a vírgula de Portugal' (grifos no original), concluindo com uma pergunta retórica: "Quem estimulou os Portugueses aos descobrimentos de países remotos, se não a estreiteza de seu território mísero e insustentável?" (GAMA, 1822a, p. 9).

O que há de mais interessante no discurso do autor é sua inversão do argumento usualmente ventilado, no que quer "jogar a bola no campo da Família Real": uma vez que o Brasil era a parte mais importante do Reino Unido, as ordens das Cortes Portuguesas para a transmigração da sede do Reino Unido a Lisboa seriam uma desonra à Coroa. A Coroa Imperial deveria estar associada à potência, ao local mais promissor, determinando-se naturalmente sua sede no Brasil - Portugal, por sua pequena extensão territorial e por ter, segundo o autor, um fluxo comercial vinte vezes inferior ao do Brasil, não seria a sede compatível com um Império. ${ }^{9}$ Como o autor já adiantava no título da primeira parte de seu opúsculo ( A privação do Poder Legislativo, e da posse do Rei, como país indecoroso para a Realeza), a transmigração para Portugal era contrária à dignidade do trono.

Um país rico, independente no todo, e independente em cada uma das suas partes, é propriamente criado pelo Autor dos destinos humanos para firmar o assento de um grande Império, em que se pode, melhor do que em Portugal, sustentar o esplendor do Trono. (...) Sim, caros irmãos Portugueses, a riqueza é a Potência (GAMA, 1822a, p. 11).

\footnotetext{
${ }^{7}$ Sobre a posição de Tomás Antônio de Vilanova Portugal, e sua controvérsia com Pedro de Sousa Holstein, o Conde de Palmela, quanto à manutenção da Corte no Rio de Janeiro ou seu retorno a Lisboa, ver: HONORATO, Fernando Henrique Lopes. Constitucionalismo em formação no Brasil: uma análise dos discursos parlamentares na Assembleia Geral Constituinte e Legislativa de 1823.2014. 146 f. Dissertação (Mestrado em Direito) —Universidade de Brasília, Brasília, 2014, pp. 21-32.

${ }^{8}$ A imagem da âncora é invocada tanto na Memória (GAMA, 1822a, p.10) quanto na Representação do Povo do Rio de Janeiro ao Príncipe Regente em Prol da Convocação de uma Assembleia Geral (BONAVIDES e AMARAL, 2002, p. 573).

${ }^{9}$ Cabe sempre lembrar que a noção de Império, no final do século XVIII e no século seguinte, possuía uma acepção positiva, sendo compatível inclusive com as ideias do Iluminismo e do Racionalismo. É nesse sentido que deve ser compreendida a defesa do Império por Bernardo José da Gama - a consolidação do Império se dá para o bem do Brasil, sendo esse sistema já tido como compatível com um regime monárquico desde Montesquieu. Vide PAGDEN, Anthony. Lords of All The World: Ideologies of Empire in Spain, Britain and France c. 1500- c. 1880. New Haven/Londres: Yale University Press, 1995, p. 10.
} 
Se o Visconde de Goiana havia se manifestado comedidamente no início de seu opúsculo a respeito da transmigração da Corte, em trechos posteriores, ele dirigiu um alerta direto à Coroa. Se a Família Real achava que o Brasil era dependente dela, deveria compreender que, apesar de o sistema monárquico ser o mais desejável, o país poderia triunfar sem ele. Uma vez desocupado o trono do Brasil, pelo retorno do Príncipe Regente a Portugal, até mesmo a despeito das "duras condições" do sistema democrático (GAMA, 1822a, p. 24), o país seria capaz de "melhorar a sua condição por qualquer forma de governo", em função de todas as suas condições naturais e econômicas vantajosas. Desse modo, se a Coroa não se aproveitasse de sua sede natural para fixar seu Império, corria o risco de perdê-la. A Monarquia dependia do Brasil, e não o contrário. A "paixão da pátria" do povo brasileiro poderia se transformar em um "desejo de glória".

\section{O Decreto de 24 de fevereiro de 1821 e o pacto social}

Passando ao exame do Decreto de 24 de fevereiro de 1821 (BRASIL, 1821, p. 22), pelo qual Dom João VI aprovara a Constituição que ainda se estava fazendo nas Cortes Portuguesas, Bernardo José da Gama tenta desconstruí-lo com fundamentos jurídicos. Afirma tratar-se o juramento do texto tal como viria a ser feito, independentemente do conhecimento prévio de seu conteúdo final, de cláusula leonina, a qual não poderia obrigar o contraente prejudicado, pois não contemplaria nenhum interesse próprio. Diz ele, então, que a cláusula "tal qual" é por sua natureza nula (GAMA, 1822a, p. 12).

O raciocínio que se segue então é discutível, mas ilustra como o autor define com pouca clareza o conteúdo do que formaria o pacto social entre Brasil e Portugal. De início, partindo de noções bem-assentadas de direito canônico sobre o juramento promissório, o autor afirma que todo juramento segue a natureza do ato que referenda, de modo que, em sendo o ato contrário ao direito, o juramento perde validade e não tem função de garantia. Contudo, sem maiores esclarecimentos, associando o pacto social a um juramento, conclui que o ato de imposição da obrigação tirânica perturbaria os termos do pacto social firmado entre Brasil e Portugal quando da elevação do primeiro à categoria de Reino, o que permitiria ao Brasil resgatar sua liberdade natural (GAMA, 1822a, p. 13).

Pode-se melhor compreender a associação feita pelo autor entre o pacto social e uma promessa quando ele, posteriormente, para defender a permanência do Príncipe Regente, afirma que D. Pedro I fora deixado no Brasil em garantia do pacto social, dando a entender que esse pacto seria perturbado com o seu retorno a Portugal (GAMA, 1822a, p. 39). Seu argumento prossegue no sentido de que a imposição tirânica das Cortes destruiria um vínculo de confiança pressuposto pela relação horizontal de irmandade entre os Reinos do Brasil e de Portugal, abrindo espaço para que o Brasil pudesse defender sua independência.

A noção de pacto social invocada por Bernardo José da Gama está ainda relacionada ao modelo do 
Antigo Regime e está longe de representar o pensamento do constitucionalismo liberal. Trata-se de um conceito referente aos limites dos poderes assumidos pelo monarca, consolidados por seu juramento. O pacto social preexiste e diz respeito ao status jurídico da nação brasileira e ao dever de proteção do Rei para com seus súditos, sendo consolidado pelo juramento régio e pela progressiva ascensão do prestígio e da soberania do Brasil - de Colônia, a Vice-Reino, a Reino.

O próprio caráter pactício, caracterizando um acordo livre, não é claro, pois o autor não inclui, em sua descrição do pacto social, uma tratativa do monarca com seus súditos. Tal descrição pode ser, inclusive, plausivelmente interpretada como uma simples concessão generosa do monarca, tal como a doutrina próabsolutista o fazia (SEELAENDER, 2006, p. 203). Desse modo, sua manifestação destoa muito da de outro texto político da época, o Oficio da Representação de São Paulo ao Príncipe Regente, de 24 de dezembro de 1821, o qual, citando as Cortes Portuguesas, afirmava que a Constituição seria o próprio pacto social pelo qual a Nação se constituiria em um corpo político (D. PEDRO I, 1822, p. 23).

As divergências sobre a preexistência de um pacto social ou sobre a função constitutiva do pacto social constituinte perduraram até mesmo durante as sessões da Assembleia Constituinte e Legislativa do Brasil, como mostra a manifestação do Deputado Antonio Carlos (HONORATO, 2014, p. 67), contrastada por outros legisladores. Não é de se estranhar que tenha havido disputas, no contexto conturbado em que se deu a convocação da assembleia brasílica: ainda em 3 de junho de 1822, antes da independência, quando Portugal e Brasil continuavam formal e politicamente vinculados. Quando da convocação da Assembleia Constituinte e Legislativa do Brasil, as manifestações régias apontavam para uma ideia reparadora, e não inovadora, no que a ideia de um pacto social inaugurado pela Constituição, embora defendida por alguns parlamentares, somente se consolidou no Brasil em momento posterior. É somente com um olhar anacrônico que o principal cronista da assembleia brasílica, o Barão Homem de Melo, podia falar sobre seus eventos que, proclamada a independência, "a consagração solene da nova ordem de coisas em um pacto social não estava ainda feita" (HOMEM DE MELO, 1863, p. 4).

Tendo em vista a ideia de um pacto social prévio, conclui Bernardo José da Gama que o Decreto de 24 de fevereiro de 1821, ao violar o pacto social que conformou o Reino do Brasil, era contrário à soberania dessa parte da nação (GAMA, 1822a, p. 33).

Tal argumento é formulado ainda mais diretamente na Representação do Povo do Rio de Janeiro ao Príncipe Regente em Prol da Convocação de uma Assembleia Geral, sem a referência expressa à ideia de um pacto social. O Brasil, ascendido ao status de Reino, não poderia ser demovido de sua condição por Portugal.

Quando uma nação muda o seu modo de existir e de pensar, não pode nem deve tornar a ser governada como era antes dessa mudança. O Brasil, elevado à categoria de reino, reconhecido por todas as potências e com todas as formalidades que fazem o direito público da Europa, tem inquestionável jus a reempossar-se da porção de soberania que lhe compete, 
porque o estabelecimento da ordem constitucional é um negócio privativo de cada povo.

(...) Se o estado de retrogradação é sempre doloroso para o indivíduo, de quanta violência, de quanto horror não será ele para um povo grande e rico (...) (BONAVIDES e AMARAL, 2002, pp. 576-577).

Ao negar eficácia ao Decreto de 24 de fevereiro de 1821, de pena do próprio Dom João VI, não estava o Visconde de Goiana a desautorizar o Rei? Muito pelo contrário. Ao afirmar que a aprovação da Constituição nos termos do Decreto de 24 de fevereiro de 1821 era inadequada, ele somente o fez em função da "exótica e inconsequente cláusula do tal qual' (GAMA, 1822a, p. 14), no que concluiu que o decreto devia ser compreendido de tal maneira que a Constituição dependeria, quando pronta, da aprovação do Rei. Ao exigir a aprovação de texto ainda não concluído, as Cortes estavam seguindo "o absurdo de mudar as leis físicas do Universo". O Visconde de Goiana formulava, então, uma apresentação jurídica da ideia posteriormente incorporada pelo Príncipe Regente no discurso de abertura da Assembleia Constituinte e Legislativa do Brasil, em 3 de maio de 1823, de que defenderia a Constituição se digna dele e do Brasil - a Constituição somente viria a aperfeiçoar o pacto social se fosse com ele compatível. Caberia ao Imperador a última palavra sobre o projeto de Constituição.

\section{O sistema monárquico-constitucional e a Constituição Brasílica}

O Visconde de Goiana acrescenta que a retirada do Poder Executivo do território brasileiro e o fim da administração centralizada, em prol de um modelo de autonomia provincial, acabariam por deixar o Brasil vulnerável aos avanços das potências europeias e por opô-lo, por fim, a Portugal. Para isso, ele resgata o exemplo de Roma, em contraste com o da Lacedemônia, associando a conduta das Cortes à ordem despótica dos romanos. Diz ele que, ao submeter uma grande periferia, o centro, cioso de manter seus privilégios, seria objeto de aversão daquela parte cuja liberdade era tolhida, a qual desejaria, então, a queda dos opressores (GAMA, 1822a, pp. 15-18). Para o autor, o retorno do Príncipe Regente a Lisboa e a desintegração dos poderes no Brasil seriam medidas contrárias à consolidação do Reino Unido como verdadeiro Império.

Considerando descabida a ideia de submeter o Brasil novamente a Portugal, o Visconde de Goiana afirma que ela somente se justificaria por um partidarismo, relacionado a um desejo de vingança ou de monopolizar as melhores funções públicas. Pondo em risco a união fraternal dos Reinos do Brasil e de Portugal, as Cortes Portuguesas estariam tomando medidas que não seriam verdadeiramente constitucionais, pois visivelmente contraditórias ao interesse de toda a Nação. Aqueles que apoiassem essas medidas deveriam ser castigados como verdadeiros motores da separação portuguesa, apoiando um sistema oculto (GAMA, 1822a, p. 17), ao invés de um sistema constitucional.

Só hum oculto espírito de partido nimiamente desordenado pelo interesse privado, ou pelo depravadíssimo gosto de dominar, poderia iniciar em Cortes uma segunda queda da 
liberdade do Brasil, despojando-o dos vasos de guerra, da artilharia, e de todos os meios de sua natural defesa, e até da Presença do Príncipe Real; medidas estas tão visivelmente contraditórias aos interesses de Portugal, e ao estado de toda a Nação, que aqueles que se animarem a defendê-las tão longe estão de serem Constitucionais, que devem ser até castigados como verdadeiros motores da separação Portuguesa (GAMA, 1822a, p. 21).

O Visconde de Goiana alerta que as acusações das Cortes Portuguesas de que "quem nos ataca, ataca a Constituição" são na realidade uma afirmação falaciosa. É contra os abusos da Constituição que os brasileiros se insurgem, o que não os qualifica como "inimigos da Constituição" (GAMA, 1822a, p. 29). A Representação do Povo do Rio de Janeiro ao Príncipe Regente em Prol da Convocação de uma Assembleia Geral é mais incisiva a esse respeito, criticando abertamente as Cortes Portuguesas: "talvez o Congresso, no devaneio de sua fúria, dará (e será uma nova inconsequência) o nome de rebelião ao passo heroico” (BONAVIDES e AMARAL, 2002, p. 576). A rejeição das Cortes Portuguesas e a manutenção da unidade do Brasil são medidas de defesa da Constituição, esta que "desejamos ver em mãos mais hábeis" (GAMA, 1822a, p. 29).

Sua proposta, nesse contexto, é que as províncias declaradas independentes pelos atos das Cortes se confederem e reafirmem sua união, restaurando o pacto social por meio de uma Constituição Brasílica. A liberdade e a segurança recíproca das províncias somente seriam afirmadas pela consolidação de um sistema monárquico-constitucional:

As ideias políticas estão hoje muito vulgarizadas por todas elas [as províncias autônomas], para nos seus exames compreenderem que a organização deste todo não poderá deixar de ser a de um só Sistema que equilibre as vantagens com a segurança recíproca, isto é, de um Sistema Monárquico-modificado por uma Constituição tal que seja compatível ao estado de liberdade, em que hoje se acham. Porquanto (torno a dizê-lo) o perderem, esta liberdade já adquirida, e já desfrutada, sem as novas vantagens de uma Constituição Brasílica, é um impossível (GAMA, 1822a, p. 41).

A defesa da Constituição, articulada em todo o opúsculo, não significa a assunção de um constitucionalismo, nos moldes das revoluções liberais dos séculos XVIII e XIX. A função da Constituição, para o autor, é a restauração das liberdades sob um regime monárquico-constitucional, o qual fora abalado pelas Cortes Portuguesas, e seu objetivo, com a Constituição Brasílica, é a reestruturação do Reino do Brasil. Embora muitos dos conteúdos básicos explanados pelo Visconde de Goiana convirjam com a concepção revolucionária, no que ele reconhece essa constituição como uma norma de funcionamento do Estado (GAMA, 1822a, pp. 44-45) ${ }^{10}$ e como uma norma de garantia de liberdades civis (GAMA, 1822a, p. 41), a Constituição Brasílica não é por ele pensada como uma norma superior, instituidora do pacto social.

Retomando Montesquieu, o Visconde de Goiana afirma que o fato de o Brasil ser um país de grande extensão não deve privá-lo do "benefício de uma boa Constituição" (GAMA, 1822a, p. 41), garantindo-se, com isso, somente, que o sistema de governo não degringole para um despotismo. Quem age despoticamente, no

\footnotetext{
${ }^{10}$ Quanto a isso, ele cita como "objetos, cuja descrição peculiar pertence à Constituição": "as disposições de forças de guerra, e diminuição delas no tempo da paz; inversões dos fundos em proporção das urgências do Estado; e outros infinitos objetos”.
} 
contexto da interpretação do Visconde de Goiana, são as Cortes, e não o monarca.

A restrição dos poderes do Príncipe Regente pelas províncias reunidas, porém, não afeta a preponderância da Coroa. Ao encerrar sua proposta de regeneração política brasileira, o Visconde de Goiana expõe finalmente a condição em que a assembleia brasílica deve ser reunida e deve produzir a Constituição Brasílica. Não se trata de órgão independente da Coroa, mas a ela subordinado, diferentemente das despóticas Cortes Portuguesas:

Então se mostrará o modo por que se deve organizar esse Corpo Legislativo, não absoluto como o de Portugal, mas sim com a preponderância do Príncipe, que é o maior interessado na conservação do Estado do que os Deputados temporários: é este o prumo com que a Inglaterra muito tem durado, até por ser o Príncipe a única garantia da liberdade, ou para melhor dizer, o único reparo dos abusos, que podem ter os mesmos Deputados (GAMA, 1822a, p. 47).

A caracterização do sistema monárquico-constitucional pelo autor, desse modo, é tal que há uma clara preeminência do Príncipe Regente sobre a assembleia brasílica. É por isso que ele critica as Cortes Portuguesas, as quais, sob o pretexto de seguirem esse modelo, teriam se inclinado para a formação de um sistema odiosamente "democrático-monárquico" (GAMA, 1822a, p. 9), pois postas as decisões constituintes fora das mãos do monarca.

\section{O patriotismo conservador e a Nação Portuguesa}

Apesar de proporem a adequação da Constituição às condições locais, e de afirmarem que somente os Deputados Brasileiros poderiam dispor sobre o sistema fundamental do país, tanto o opúsculo quanto a Representação do Povo do Rio de Janeiro ao Príncipe Regente em Prol da Convocação de uma Assembleia Geral ainda fazem referência à noção de uma Nação Portuguesa - assim como as Cortes o faziam -, a qual seria formada por Portugal e Brasil, e não a duas distintas nações com um governo unificado.

Como então conciliar a proposta de se preparar um sistema fundamental para o Brasil com o fato de haver uma única Nação, junto a Portugal e às demais partes do Reino Unido? Como admitir que uma parte da Nação dê a ela própria um sistema fundamental?

Para driblar esse problema, o Visconde de Goiana lida com uma complexa e pouco usual tipologia: apesar de afirmar que o Brasil é somente uma parte da Nação Portuguesa (GAMA, 1822a, pp. 16 e 33), ele reconhece repetidamente o Brasil como um país (GAMA, 1822a, pp. 9, 11, 16, 20, 32 e 44) e invoca por vezes a pátria (GAMA, 1822a, pp. 24 e 31) brasileira, conferindo diferentes conteúdos a esses conceitos.

Na obra, o autor já se refere a um conceito maduro de Nação, incorporando elementos jurídicos, políticos e culturais à sua definição, à moda do ideal racionalista do Estado-Nação. Assim, ao elemento nacional corresponde, na obra, uma noção histórica e cultural, de uma linhagem comum e de um futuro compartilhado 
(GAMA, 1822a, p. 25). Ademais, a Nação também é a sede da soberania, no que o Brasil somente detém uma parcela da soberania nacional e no que a Nação Portuguesa é o ator político na esfera internacional, sendo ela vinculada pelos tratados internacionais (GAMA, 1822a, p. 12).

De modo a excluir certos conteúdos políticos da apreciação da Nação, o autor faz uso do vocábulo país de forma pouco usual, considerando que parte da legislação deve dizer respeito somente a ele, em razão das condições próprias e específicas. Assim, certas decisões políticas devem ser tomadas exclusivamente pelo Brasil, sem a interferência de outra parte da Nação Portuguesa: "só á estes deputados do Brasil, digo, pertencia o proporcionar bem uma legislação ao seu país" (GAMA, 1822a, p. 32).

No que diz respeito à função histórica e cultural da nação, o autor faz referência a outro conceito para contrabalançá-la em favor de suas partes. Trata-se da ideia de uma pátria exclusivamente brasileira. $\mathrm{O}$ amor à pátria e a obrigação de salvar a pátria são invocados pelo Visconde de Goiana como fórmulas apelativas para que os Brasileiros não sucumbam às ofertas que prejudicam a glória do país, consolidando um sentimento comunitarista de filiação à terra e de pertencimento ao território, referente à patria loci (CATROGA, 2011, p. 14), mas ainda não à patria civitatis.

Esse recurso ao patriotismo, diferentemente dos revolucionários liberais, serve a esse conservador como justificativa para a restauração, consolidando a pátria como bastião da resistência contra o alegado despotismo de outra parte da Nação, como ensina Fernando Catroga:

$\mathrm{Na}$ verdade, as lutas contra o absolutismo e o imperialismo napoleônico, assim como os movimentos que levarão à gênese de novas nações (em particular, a partir de antigas colônias da América), despertaram várias acepções de sentimentos patrióticos como atitude de resistência, mesmo naqueles que o fizeram por fidelidade às suas "constituições" históricas e aos garantes tradicionais da pátria comum (a Igreja e a Monarquia, como aconteceu nos países ibéricos durante as lutas contra Napoleão, "o usurpador") (CATROGA, 2011, p. 21).

Patriota sim, mas não revolucionária. A Memória de Bernardo José da Gama fazia questão de condenar os atos despóticos das Cortes, mas defendia que os brasileiros não agiam por rebeldia, mas pelo bem do pacto social e da Constituição. Não propunha uma cisão imediata com Portugal, mas uma condenação das medidas das Cortes Portuguesas.

A ideia de uma manutenção dos vínculos com Portugal, mas da garantia de espaços propriamente brasileiros, parece justificar a rara nomenclatura adotada pelo Visconde de Goiana, para quem há uma pátria brasileira sem uma nação equivalente e um país dos brasileiros ainda vinculado à nação portuguesa. $\mathrm{O}$ interesse em uma reconciliação com os irmãos portugueses justifica a exclusão de quaisquer referências à nação brasileira, e mostra o esmero do Visconde de Goiana em sugerir a ruptura com as Cortes e a instalação de um Corpo Legislativo no Brasil, sem se incompatibilizar com a Coroa. 


\section{CONCLUSÃO}

O opúsculo de Bernardo José da Gama poderia muito bem se configurar como uma exposição da doutrina oficial para os eventos que se desenrolaram no primeiro semestre de 1822, com a permanência do Príncipe Regente no Brasil, o rompimento com as Cortes Portuguesas e a convocação da Assembleia Constituinte e Legislativa do Brasil. A "Regeneração do Brasil" (GAMA, 1822a, p. 47), objetivo-síntese do escrito, é uma restauração conservadora do Reino do Brasil, sem uma desvinculação da Nação Portuguesa e com a manutenção da preeminência régia. Até mesmo a proposta de uma Constituição Brasílica faz parte da dita regeneração, como forma de reequilibrar as relações entre as distintas partes da Nação.

Examinando a caracterização da assembleia das províncias, do pacto social e da constituição, como propostas por Bernardo José da Gama, não é de se estranhar que a proposta de criação da Assembleia Constituinte e Legislativa pudesse ter sido acatada pela Coroa. Sua Memória exemplifica o pensamento conservador de então, o qual admitia a Constituinte como um ajuste excepcional diante de uma conduta despótica de parcela da Nação, tal qual uma Revolução Gloriosa no Brasil, se pensarmos na caracterização de Edmund Burke (BURKE, 1982). De mais a mais, o sistema monárquico-constitucional, em sua vertente conservadora, era tal que a assembleia brasílica, por mais que pudesse restringir os poderes do monarca, sempre dependia da aprovação da Coroa, tanto para sua organização, quanto para a aprovação de seu projeto final. Pendia a equação para a prevalência monárquica, com um efeito meramente reparador do texto constitucional.

$\mathrm{Na}$ obra, inserida em um pensamento da restauração, tanto a constituição quanto o pacto social aparecem como novidades terminológicas, mas sem a correspondente mudança ideológica, pouco se distinguindo do modelo do Antigo Regime das Leis Fundamentais disciplinadas nas Cortes Régias. A ausência de uma concepção firme sobre o papel da constituição e sobre a formação do pacto social exemplificam as dificuldades por que a Assembleia Constituinte e Legislativa do Brasil viria a passar, na difícil tarefa de distinguir efetivamente o que deveria tratar enquanto Legislativa daquilo que deveria tratar enquanto Constituinte.

\section{FOR THE DIGNITY OF THE THRONE AND THE REGENERATION OF THE SOCIAL PACT: VISCOUNT OF GOIANA'S MÉMOIRE TO EMPEROR PEDRO I}

\section{Abstract}

The article analyses Viscount of Goiana's Mémoire (Memoir on the main causes, why should Brazil reassume its rights, and reunite its provinces) in order to illustrate how the summoning of the 1823 Constituent Assembly could be deemed compatible with a conservative reading of the Brazilian monarchic-constitutional regime.

Keywords: 1823 National Constituent and Legislative Assembly, Viscount of Goiana, conservatism, vol.10, nº. 02, Rio de Janeiro, 2017.pp. 801-817 
constitutional monarchy

\section{REFERENCIAS}

BASILE, Marcello. A Revolução do 7 de Abril de 1831: disputas políticas e lutas de representações. In: XXVII SIMPÓSIO NACIONAL DE HISTÓRIA, 2013, Natal/RN. Anais do XXVII Simpósio Nacional de História Conhecimento histórico e diálogo social Natal: UFRN, 2013. Disponível em: http://www.snh2013.anpuh.org/resources/anais/27/1364533003_ARQUIVO_Art-ANPUH2013-

MarcelloBasile.pdf. Último acesso em: 13 de fevereiro de 2016.

BLAKE, Augusto Victorino Alves Sacramento. Diccionario bibliographico brazileiro. Vol. 1. Rio de Janeiro: Typographia Nacional, 1883. Disponível em: http://bd.camara.gov.br/bd/handle/bdcamara/14856. Último acesso em 16 de fevereiro de 2016.

BERNARDES, Denis. O patriotismo constitucional: Pernambuco, 1820-1822. São Paulo/Recife: FAPESP/UFPE, 2006.

BONAVIDES, Paulo; AMARAL, Roberto. Textos Políticos da História do Brasil. Vol. 1. 3ª. Ed. Brasília: Senado Federal, 2002.

BRASIL. Assembleia Geral, Constituinte e Legislativa (1823). Diário da Assembleia Geral, Constituinte e Legislativa do Império do Brasil, 1823. Tomo I. Brasília: Senado Federal, Conselho Editorial, 2003.

BRASIL. Coleção de Leis do Império do Brasil. Vol. 1. Pt. II. Rio de Janeiro: Imprensa Nacional, 1821. Disponível em: http://www2.camara.leg.br/legin/fed/decret_sn/anterioresa 1824/decreto-39220-24-fevereiro-1821569031-publicacaooriginal-92323-pe.html. Último acesso em: 14 de fevereiro de 2016.

Ministério do Reino e dos Negócios Estrangeiros do Império do Brasil. Representações que, a' Augusta Presença de Sua Alteza Real, o Principe Regente do Brasil, levarão o Governo, Senado da Camara, e Clero de S. Paulo; por meio de seus respectivos Deputados; com o Discurso, que, em Audiência Pública do dia 26 de janeiro de 1822, dirigio em nome de todos ao Mesmo Augusto Senhor, o Conselheiro José Bonifácio d'Andrada e Silva, Ministro, e Secretario d'Estado dos Negocios do Reino, e Estrangeiros. Rio de Janeiro: Imprensa Nacional, 1822. Disponível em: http://www.obrabonifacio.com.br/colecao/obra/1271/digitalizacao/. Último acesso em: 14 de fevereiro de 2016.

BURKE, Edmund. Reflexões sobre a Revolução em França. Brasília: Ed. UnB, 1982.

CAMARGO, Ana Maria de Almeida; MORAES, Rubens Borba de. Bibliografia da Impressão Régia do Rio de Janeiro. São Paulo: EDUSP/Kosmos, 1993.

CATROGA, Fernando. Pátria e Nação. In: VII JORNADA SETECENTISTA, 2007, Curitiba/PR. Temas Setecentistas. Curitiba: CEDOPE/UFPR, 2011. Disponível em: http://www.humanas.ufpr.br/portal/cedope/files/2011/12/P\%C3\%A1 tria-e-Na\%C3\%A7\%C3\%A3oFernando-Catroga.pdf. Último acesso em: 13 de fevereiro de 2016.

COSTA, Francisco Augusto Pereira da. Diccionario biographico de pernambucanos celebres. Recife: Typographia Universal, 1882. 
D. PEDRO I, IMPERADOR DO BRASIL. Cartas, e mais Peças Officiaes, Dirigidas a S. Magestade o Senhor D. João VI pelo Principe Real o Senhor D. Pedro de Alcantara. Lisboa: Imprensa Nacional, 1822. Disponível em: http://www2.senado.leg.br/bdsf/item/id/179480. Último acesso em: 15 de fevereiro de 2016.

FELDMAN, Ariel. A mesma independência: a atuação pública de um unitário pernambucano (1822-1823). Revista Tempo, Rio de Janeiro, Vol. 20, 2014.

FERREIRA, Fernando Luiz Vieira. Juízes e Tribunais do Primeiro Império e da Regência. Boletim do IHGB. Rio de Janeiro: Imprensa Nacional, 1937.

GAMA, Bernardo José da. Memoria sobre as principaes cauzas, por que deve o Brasil reassumir os seus direitos, e reunir as suas províncias. Rio de Janeiro: Typographia Nacional, 1822a. Disponível em: http://www2.senado.leg.br/bdsf/item/id/185625. Último acesso em 05 de fevereiro de 2016.

Resposta à Malagueta no. XII. Rio de Janeiro: Typographia Nacional, 1822b.

GAZETA DO RIO DE JANEIRO. Gazeta do Rio de Janeiro, 1819-1822. Rio de Janeiro: Imprensa Régia, 1822. HOMEM DE MELO, Francisco Inácio Marcondes. A Constituinte perante a História. Rio de Janeiro: Typographia da Actualidade, 1863.

HONORATO, Fernando Henrique Lopes. Constitucionalismo em formação no Brasil: uma análise dos discursos parlamentares na Assembleia Geral Constituinte e Legislativa de 1823. 2014. 146 f. Dissertação (Mestrado em Direito) —Universidade de Brasília, Brasília, 2014.

LISBOA, João Soares. Correio do Rio de Janeiro, Rio de Janeiro, no. 62, 27 de junho de 1822.

História dos principais sucessos políticos do Império do Brasil, dedicada ao senhor Dom Pedro I. Parte X,

Seção III. Rio de Janeiro: Typographia Imperial e Nacional, 1830. Disponível em: http://www2.senado.leg.br/bdsf/item/id/182900. Último acesso em 14 de fevereiro de 2016.

NEVES, Lúcia Maria Pereira das. Corcundas e constitucionais: a cultura política da independência (1820-1822). Rio de Janeiro: Revan/FAPERJ, 2003.

PAGDEN, Anthony. Lords of All The World: Ideologies of Empire in Spain, Britain and France c. 1500- c. 1880. New Haven/Londres: Yale University Press, 1995.

PINTO FERREIRA, Luiz. A Faculdade de Direito e a Escola do Recife. Revista de Informação Legislativa, Brasilia, Ano 14, No. 55, 1977.

RODRIGUES, José Honório. A Assembleia Constituinte de 1823. Petrópolis: Vozes, 1974.

SEELAENDER, Airton. Notas sobre a constituição do direito público na idade moderna: a doutrina das leis fundamentais. Revista Sequência, Florianópolis, No. 53, 2006.

VIANNA, Hélio. Vultos do Império. Rio de Janeiro: Companhia Nacional, 1968.

Trabalho enviado em 22 de agosto de 2016.

Aceito em 05 de fevereiro de 2017. 